\title{
Arc Root Mobility on Piezoelectrically Actuated Contacts in Miniature Circuit Breakers
}

\author{
Paul M. Weaver, Kesorn Pechrach, and John W. McBride
}

\begin{abstract}
A novel contact opening mechanism has been developed using a piezoelectric actuator to open the contacts in a low contact opening velocity circuit breaker. The arc control on the contacts is critical for successful current interruption $\left(10^{3}-10^{4} \mathrm{~A}\right)$ in low voltage $(<250 \mathrm{~V})$ devices. Previous work has shown how arc root commutation from the contact region into the arc chamber is affected by arc chamber materials, contact materials and the gap behind the moving contact for contact velocities between $1 \mathrm{~ms}^{-1}$ and $10 \mathrm{~ms}^{-1}$. This work is extended using a commercially available piezoelectric actuator to open the contacts. Contact opening speeds are assessed and the arc root mobility is characterized under this operating regime. A flexible test apparatus and solid-state high-speed arc imaging system are used to gather data on the arc root during the opening of the contacts. New experimental results are presented on the anode and cathode root velocity and arc root motion in an arc chamber with piezoelectrically actuated contact opening. These results can be used to improve the design of high current low voltage circuit breakers suitable for piezoelectric actuation.
\end{abstract}

Index Terms-Circuit breakers, piezoelectric actuator.

\section{INTRODUCTION}

$\mathbf{L}$ OW voltage miniature circuit breakers (MCBs) are widely used for protection from electrical faults in domestic and light industrial installations. These devices protect against short circuit faults of typically $1-16 \mathrm{kA}$. During a short circuit fault an electric arc is drawn between opening contacts. The arc is then propelled by electromagnetic forces into splitter plates which divide the arc into a number of smaller arcs. This results in a high arc voltage, which counteracts the supply voltage to limit the peak fault current. The energy released by the fault is reduced and damage to both the circuit and the circuit breaker is minimized.

To achieve satisfactory short circuit performance rapid contact opening and a high contact velocity are usually necessary. At low contact opening velocity, the arc root stays on the contacts for a longer period of time. Heat is generated in the arc chamber and the contacts are eroded. This has resulted in a range of devices where the opening mechanism is driven by a solenoid energised by the short circuit current. The solenoid plunger

Manuscript received February 1, 2005; revised October 1, 2005. This work was supported by the EPSRC and Chugai (USA). This work was recommended for publication by Associate Editor M. Braunovic upon evaluation of the reviewers' comments.

P. M. Weaver is with the School of Engineering Science, Electro-Mechanical Research Group, University of Southampton, Southampton S017 1BJ, U.K. He is also with Servocell, Ltd., Harlow CM20 2BN, U.K.

K. Pechrach is with Ronsek, Ltd., Hertfordshire CM23 5LE, U.K.

J. W. McBride is with the School of Engineering Science, Electro-Mechanical Research Group, University of Southampton, Southampton S017 1BJ, U.K. (e-mail: jwm@soton.ac.uk)

Digital Object Identifier 10.1109/TCAPT.2005.861119 not only trips the spring driven opening mechanism, but also directly drives the opening of the contacts. This "hammer action" provides a very rapid acceleration of the moving contact during the initial contact opening.

In addition to the high current event the circuit breaker must also trip on moderate over-current. This is usually achieved with a bimetallic strip. Increasingly, circuit protection devices provide additional functionality such as residual current or arc fault detection.

The design of these systems could be simplified by the use of smart materials technology to provide the contact actuation. The closer the match between actuator performance and the demands of the contact system, the simpler the operating mechanism becomes. The number of mechanical parts can be minimized, and the demands on their performance reduced. This will improve reliability, reduce size, power consumption and manufacturing costs. As well as benefits in the design of conventional circuit breakers, the ability to make solid state contact opening mechanisms would allow substantial miniaturization of these devices resulting in a completely new type of device.

The relationship between the arc mobility and the contact opening velocity is complex and depends on the magnetic environment in the arc chamber and the flow of the arc chamber gases. These effects have been investigated previously at reduced contact opening velocity [1]-[4]. It was found that adverse gas flow effects can impede the arc root motion, and that optimization of the arc chamber design could permit the use of lower contact opening velocities. Recent investigations [4] have shown that detailed study of the arc-root phenomena can yield improvements in arc chamber performance thus permitting operation at reduced contact opening velocity. This now opens the possibility of refinement of the mechanism using smart materials actuation. Piezoelectric ceramic actuators have been used as the trip element in commercial circuit breakers [5] to provide low power electronic actuation. In this paper, the operating characteristics of a piezoelectric actuator relevant to direct contact opening are presented. A directly acting contact opening system was developed. The performance of the contact system under short circuit conditions is analyzed using the flexible test system and arc imaging system described previously [1]-[4]. Results are compared with reference data using a constant opening velocity contact system. Successful current limiting performance is demonstrated using the piezoelectrically actuated contact system.

\section{Piezoelectric Actuation IN Circuit BREAKers}

The actuator used for the present investigation was a planar bimorph actuator shown in Fig. 1. The actuator employs a novel geometry, which produces very large movement from a simple 


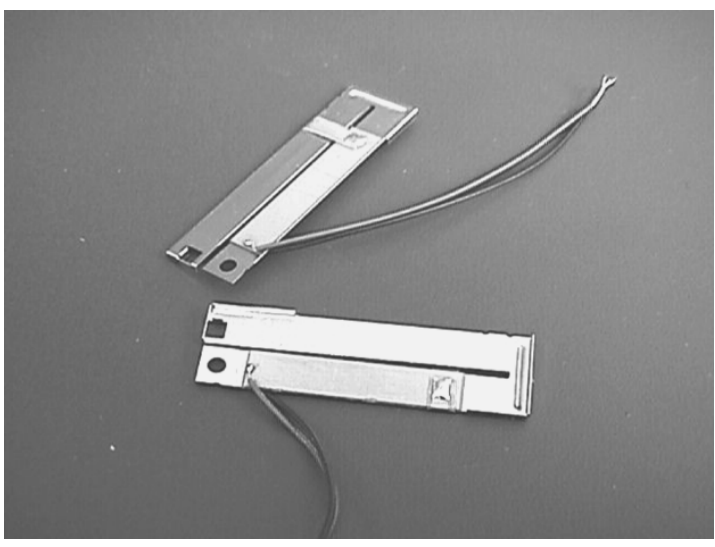

Fig. 1. Planar bimorph actuator.

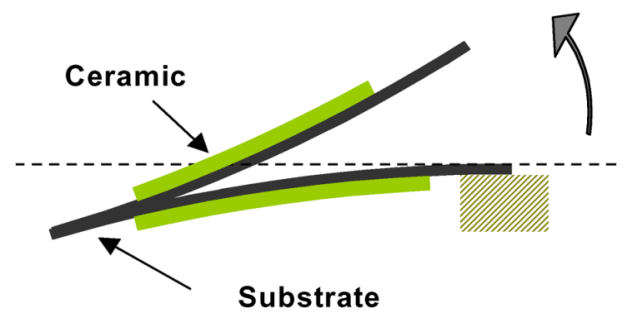

Fig. 2. Schematic diagram of the operation of the planar bimorph actuator. (Color version available online at http://ieeexplore.ieee.org.)

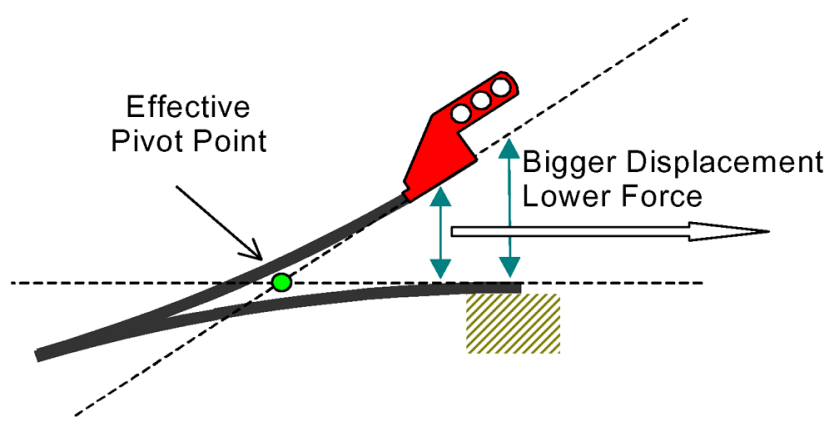

Fig. 3. Effective pivot in planar bimorph actuator. (Color version available online at http://ieeexplore.ieee.org.)

and compact structure [5]. The operating principle is shown in Fig. 2.

The actuator comprises two arms formed from a single metal substrate and two piezoelectric ceramic plates. The planar disposition of the two ceramic plates means that, unlike a conventional bimorph structure, high fields can be applied without danger of repolarising the ceramic. The first arm of the actuator produces a downward movement which provides an angle for the movement amplification of the second arm. The total movement is slightly less than could be obtained from a single beam of twice the length. However, the stiffness of a single beam has cubic relationship to the length, so only very low forces could be obtained this way. A key advantage of the planar bimorph structure is that it forms an effective pivot point approximately half way along the length of the actuator as shown in Fig. 3.

This means that a high displacement can be obtained with useful force output. This results in a much more efficient actuator than a conventional single beam design.

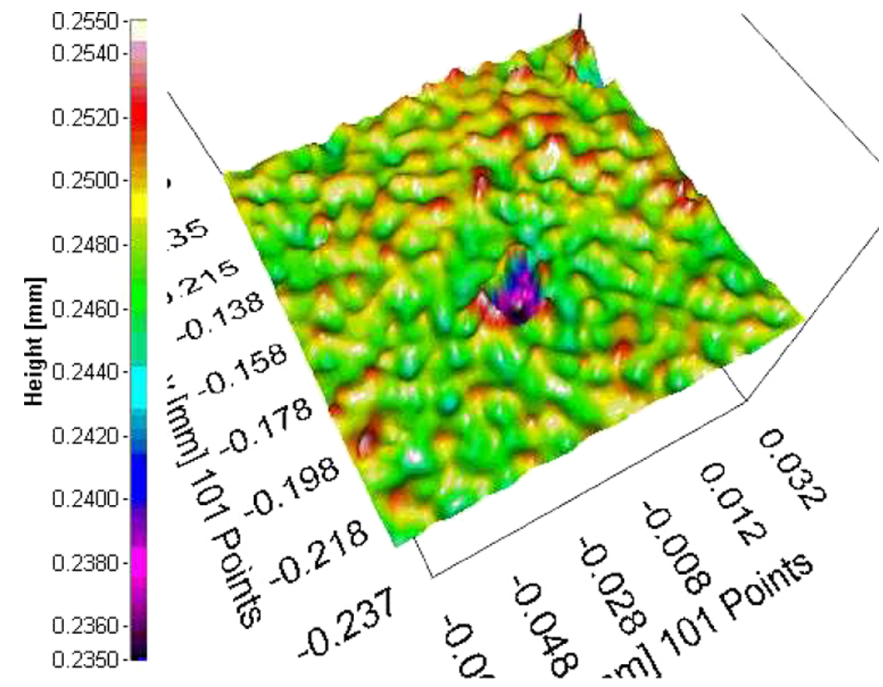

Fig. 4. Surface structure of piezoelectric ceramic (Image courtesy Taicaan Technologies www.taicaan.com). (Color version available online at http:// ieeexplore.ieee.org.)

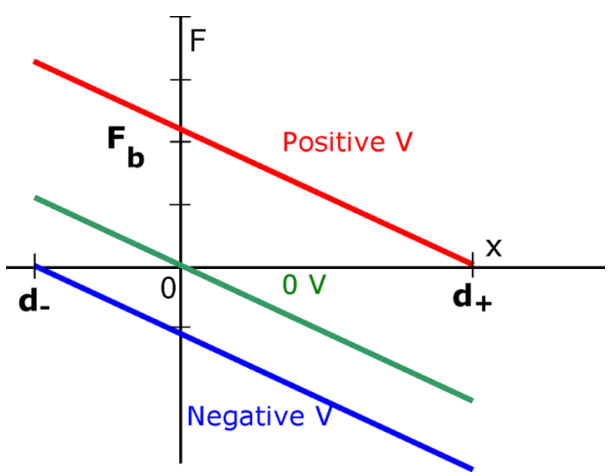

Fig. 5. Schematic of the spring model of piezoelectric actuator. The force $(\mathrm{F})$ varies linearly with displacement of the actuator tip $(x) . d_{+}$is the free positive displacement and $\mathrm{d}$ - the free negative displacement. $\mathrm{F}_{b}$ is the blocked force. (Color version available online at http://ieeexplore.ieee.org.)

The piezoelectric ceramic is a commercial grade lead zirconate titanate. It is selected for its high $d_{31}$ coefficient $\left(-330 \mathrm{pm} \mathrm{V}^{-1}\right)$ to achieve a large displacement in a bending actuator. The formed and compacted ceramic is sintered, then machined to size (see [6] for details of electro-ceramic processing). This forms a dense grain structure with typical grain sizes of $15-\mu \mathrm{m}$ diameter, as shown in the surface profile of Fig. 4. A metallic electrode is then applied to the ceramic. The ceramic plates are bonded to the metal substrate and electrical connections made to complete the assembled actuator.

When applied in a circuit breaker mechanism the actuator behavior can be approximated by a simple mass-spring system. The spring rate is independent of the applied voltage, but the unloaded position varies with voltage as shown in Fig. 5. Values for $\mathrm{F}_{\mathrm{b}}$ and $d_{0}$ for the conditions of interest are given in Table I.

A negative voltage can be applied to considerably extend the operating range of the actuator up to a limit determined by the coercive field of the ceramic [7]. Only positive voltages are considered in this paper.

The static spring characteristic of the actuator is described by the following equation relating the force, $\mathrm{F}$, and deflection $\mathrm{x}$ :

$$
F=k\left[d_{0}(V)-x\right]
$$


TABLE I

Piezoelectric ACTUATOR PERFormance CHARACTERISTICS

\begin{tabular}{|l|l|l|l|}
\hline Parameter & Description & Value & Unit \\
\hline $\mathrm{d} 0(0-400 \mathrm{~V})$ & Free displacement & 1.2 & $\mathrm{Mm}$ \\
\hline $\mathrm{k}$ & Spring constant & 0.2 & $\mathrm{~N} \mathrm{~mm}-1$ \\
\hline $\mathrm{F}_{\mathrm{b}}$ & Blocked force & 0.24 & $\mathrm{~N}$ \\
\hline $\mathrm{f}_{0}$ & Resonant frequency & 170 & $\mathrm{~Hz}$ \\
\hline $\mathrm{m}_{\mathrm{eff}}$ & Effective mass & 0.17 & $\mathrm{~g}$ \\
\hline $\mathrm{C}$ & Capacitance & 35 & $\mathrm{nF}$ \\
\hline
\end{tabular}

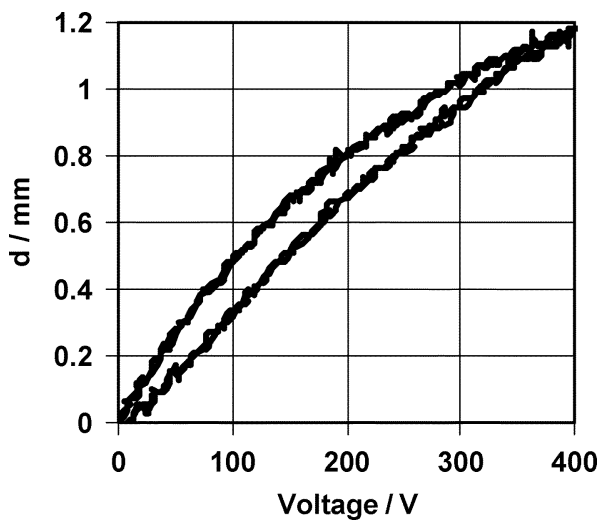

Fig. 6. Voltage response of the planar bimorph actuator.

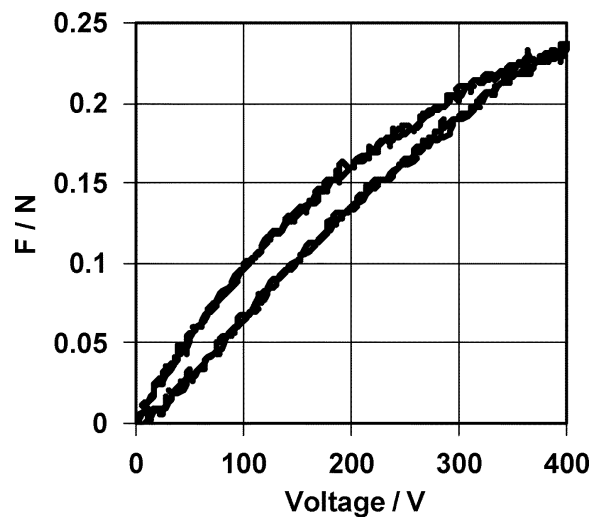

Fig. 7. Force response of the planar bimorph actuator.

where $d_{0}$ is the voltage dependent free displacement of the actuator and $\mathrm{k}$ is the spring constant. The blocked force, $\mathrm{F}_{\mathrm{b}}$ is given by

$$
F_{b}=k d_{0} .
$$

Fig. 6 shows the measured voltage response of the piezoelectric actuator [8]. Displacement results were measured using a laser displacement sensor. Force data obtained from the displacement using (2) is shown in Fig. 7.

This particular actuator had a stroke of $1.2 \mathrm{~mm}$ for the $400-\mathrm{V}$ $0.5-\mathrm{Hz}$ triangle wave used. The actuator stroke can be extended

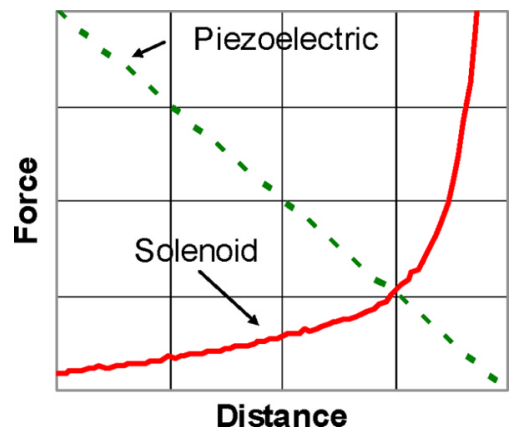

Fig. 8. Schematic of the force displacement profiles of piezoelectric and solenoid actuators. (Color version available online at http://ieeexplore.iee.org.)

by electronic means or by mechanical extension (Fig. 3). The dynamic stroke will be considerably larger than this particularly at resonance. In common with all piezoelectric actuators, hysteresis and nonlinearity are observed in the voltage response of the actuator [9] and this must be accounted for in the design.

The spring-like characteristic of the piezoelectric actuator is different to that of the solenoid or electromagnet conventionally used in circuit breaker designs as described schematically in Fig. 8. The high initial force of the piezoelectric actuator can be useful in overcoming friction and initiating mechanism movement. The slow linear decay in force is in contrast to the highly nonlinear force profile of a solenoid. In general, a solenoid will need to be specified with a high peak force to provide a useful force at a large displacement. This can result in quite a large solenoid with high power consumption. Alternatively the mechanism needs to be accurately specified to operate in the high force region of the solenoid characteristic which may require expensive processing.

In a circuit breaker, the dynamic response of the actuator is critical to the rapid operation of the mechanism. The dynamic response of the actuator was measured using a laser displacement sensor at the actuator tip. Typical results are shown in Fig. 9.

The lightly damped actuator oscillates freely with a period of $5.8 \mathrm{~ms}$, i.e. a resonant frequency of approximately $170 \mathrm{~Hz}$. The response time of $2.4 \mathrm{~ms}$ was measured as the time taken to first pass the equilibrium displacement. The velocity and acceleration of the actuator were obtained by differentiation of the displacement profile. Results are shown in Fig. 10.

The peak velocity $V_{\max }$ and peak acceleration $A_{\max }$ is approximately $0.9 \mathrm{~m} / \mathrm{s}$ and $1000 \mathrm{~m} / \mathrm{s}^{2}$, respectively. The high initial acceleration in the mechanism is valuable in achieving short opening times. Solenoid systems have intrinsically lower initial acceleration. These figures can be obtained analytically from the equations for simple harmonic motion

$$
\begin{array}{ll}
d=d_{0} \operatorname{Sin}(\omega t) & d_{\max }=d_{0} \\
v=\omega d_{0} \operatorname{Cos}(\omega t) & v_{\max }=\omega d_{0} \\
a=-\omega^{2} d_{0} \operatorname{Sin}(\omega t) & a_{\max }=\omega^{2} d_{0}
\end{array}
$$

where $\omega$ is the angular velocity $\omega=2 \pi \mathrm{F}$. From the above measurements of frequency and displacement, we obtain predicted figures of $1.3 \mathrm{~m} / \mathrm{s}$ and $1410 \mathrm{~m} / \mathrm{s}^{2}$ for the peak velocity and acceleration. These are slightly higher than the measured values due to damping in the system. 


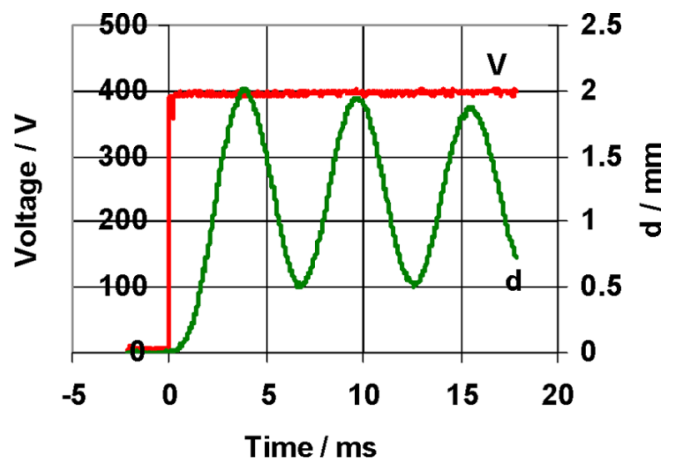

(A)

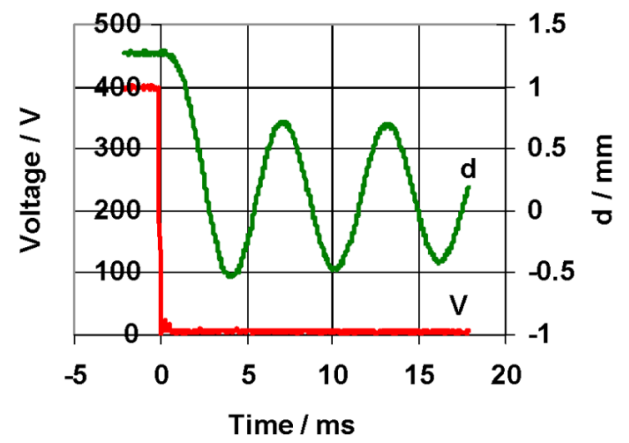

(B)

Fig. 9. Dynamic response of the actuator to rising and falling voltage steps. (a) Rising state. (b) Falling state. (Color version available online at http:// ieeexplore.ieee.org.)

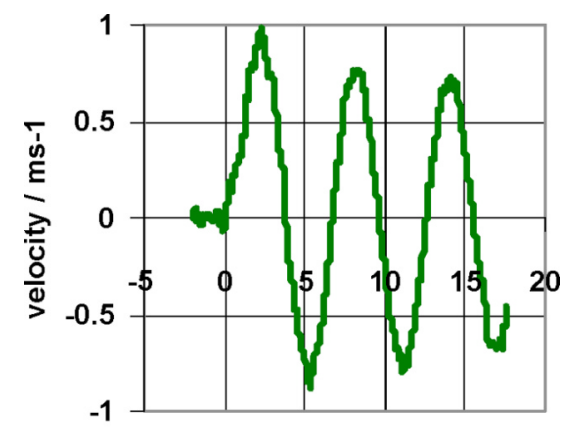

Time / ms

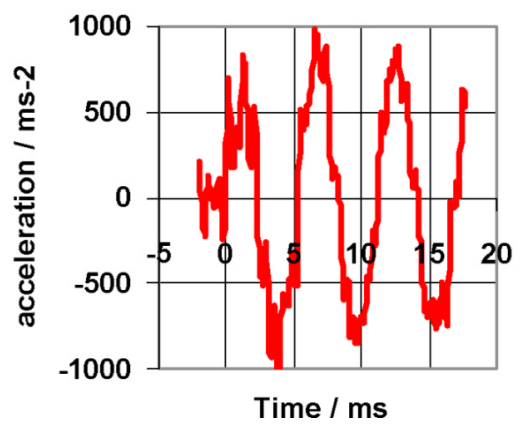

Fig. 10. Velocity and acceleration of the actuator. (Color version available online at http://ieeexplore.ieee.org.)

In a circuit breaker, the actuator would be coupled to a mechanism and this will play a large part in the dynamics of the system. To design the mechanism and predict its performance, the actuator can be built into a complete system model as a mass spring system. The spring rate and free deflection of the actuator are

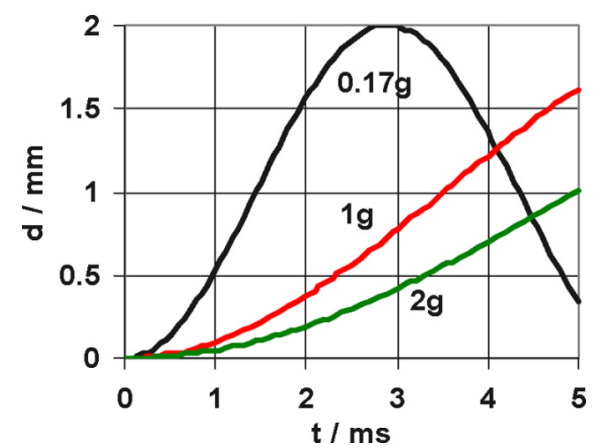

Fig. 11. Effect of contact mass on opening trajectory. (Color version available online at http://ieeexplore.ieee.org.)

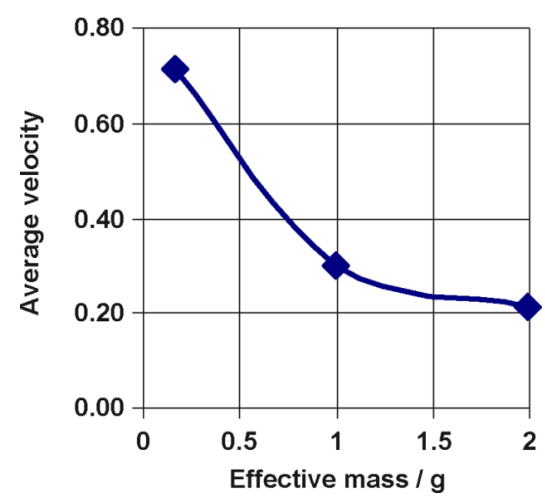

Fig. 12. Effect of contact mass on average contact velocity (velocity calculated over the first $1 \mathrm{~mm}$ of opening). (Color version available online at http:// ieeexplore.ieee.org.)

described above. The effective mass of the actuator can be obtained from the resonant frequency by assuming a simple harmonic oscillator

$$
\tau=2 \pi \sqrt{\frac{m_{\mathrm{eff}}}{k}}
$$

where $\tau$ is the period of oscillation, $\mathrm{m}_{\mathrm{eff}}$ is the effective mass of the actuator and $\mathrm{k}$ is the stiffness or spring rate of the actuator. This equation is used to calculate the effective mass of the actuator given in Table I. These figures apply to the actuator on its own. The mass of the moving contact will have a significant effect the value of $\mathrm{m}_{\mathrm{eff}}$ and therefore on the dynamics as shown in Fig. 11.

The piezoelectric actuator described here has sufficient movement to open directly a set of contacts. However, the contact velocity (Fig. 12) is below that normally required for effective current limitation. However, recent research [4] has shown that it may be possible to improve arc control to an extent that it may be possible to obtain effective arc control with contact velocities of the order of $1 \mathrm{~ms}^{-1}$. This could permit direct actuation using a piezoelectric actuator. The stroke of the actuator studied here is in the right order of magnitude for a contact system, but marginal for a short circuit device. The force from the actuator would also be insufficient for direct contact action.

Force and displacement can be improved preferably by improving the performance of the actuator but also by using the actuator as an intermediate stage in the mechanism. The discrepancy between the actuator performance and the requirements of the contact system needs to be minimized to provide the simplest mechanical system. The ultimate goal of the research is to 


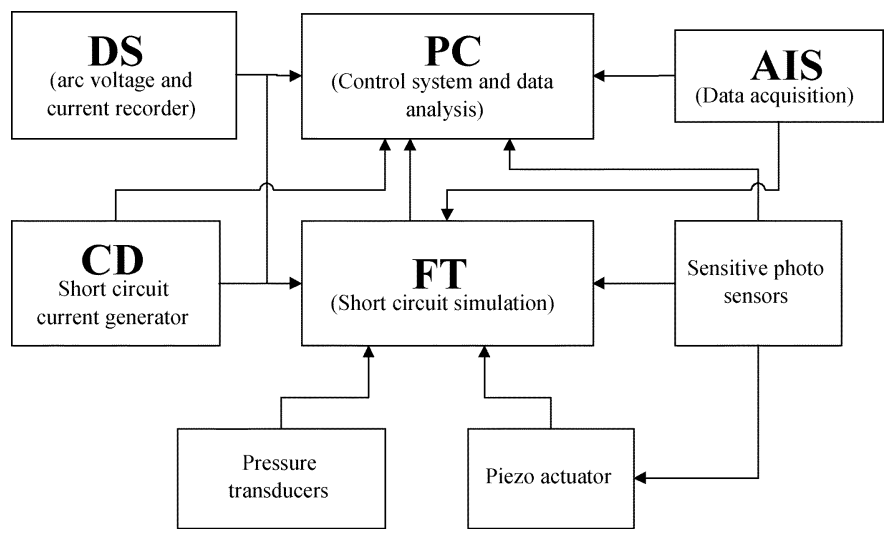

Fig. 13. Schematic diagram showing the arrangement of the apparatus and associated instrumentation.

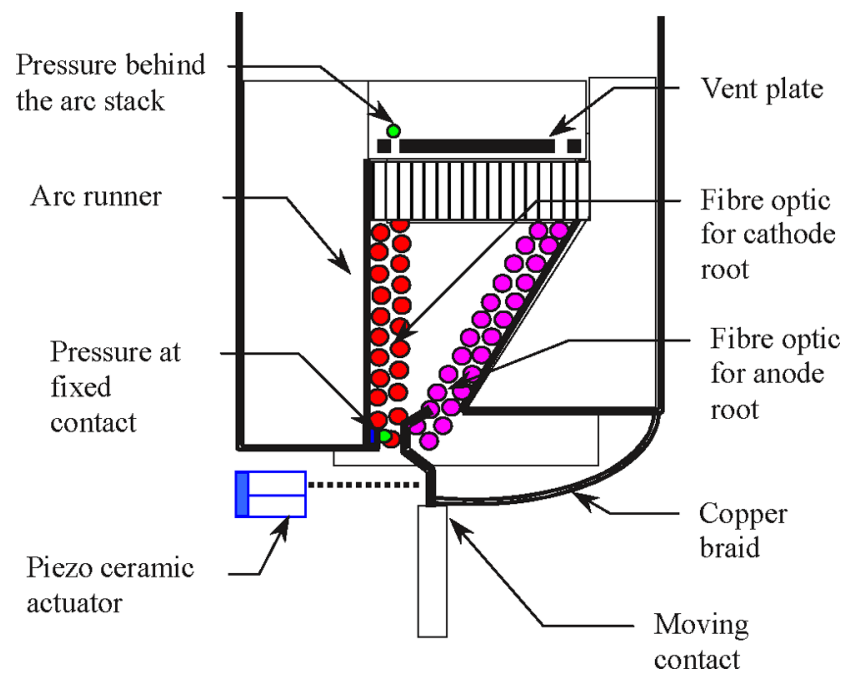

Fig. 14. Schematic diagram of the flexible test apparatus and piezoelectric ceramic actuator. (Color version available online at http://ieeexplore.iee.org.)

eliminate intermediate stages thus permitting direct contact actuation and the design of a solid state circuit breaker. It should be noted that both actuator performance and arc chamber characteristics are highly configurable by selection of geometry, materials and operating conditions. There is considerable scope therefore to optimize the matching of the characteristics of the piezoelectric actuator and the mechanical contact system to yield significant improvements in performance.

\section{Short Circuit Test Methods}

A schematic diagram of the experimental apparatus and associated instrumentation is shown in Fig. 13.

Short circuit tests were carried out using a flexible test apparatus (FTA) and arc imaging system (AIS). The test system has been described in detail previously [1]-[4]. The system simulates the current limiting operation of a miniature circuit breaker using a capacitor discharge through a variable geometry test chamber. The high speed arc imaging system (AIS) uses an optical fiber array to record the motion of the arc. The experimental test chamber is shown in Fig. 14 with the arrangement of the optical fibers used for the evaluation of the arc root motion [3]. The key experimental parameters are shown in Table II.
TABLE II

VALUES OF CONSTANT FACTORS USED FOR ALL EXPERIMENTS

\begin{tabular}{|l|l|}
\hline Constant factors & Value \\
\hline Charge voltage & $340 \mathrm{~V}$ \\
\hline Inductance & $224 \mu \mathrm{H}$ \\
\hline Capacitance & $47.4 \mathrm{mF}$ \\
\hline Final contact gap & $6 \mathrm{~mm}$ \\
\hline $\begin{array}{l}\text { Peak short circuit } \\
\text { current }\end{array}$ & $2000 \mathrm{~A}$. \\
\hline Moving contact & $\begin{array}{l}\text { Silver plated copper } \\
2.3 \mathrm{~g}\end{array}$ \\
\hline Contact polarity & $\begin{array}{l}\text { Anode (moving } \\
\text { contact) Cathode } \\
\text { (fixed contact) }\end{array}$ \\
\hline Chamber depth & $6 \mathrm{~mm}$ \\
\hline Arc stack displacement & $35 \mathrm{~mm}$ \\
\hline
\end{tabular}

Experiments were performed using a piezoelectric actuator with a contact piece attached to the moving end. For comparison, tests were also conducted using a constant contact opening velocity of $1 \mathrm{~ms}^{-1}$. This was driven by a pivoting mechanism powered by a large solenoid as described previously [4].

\section{RESULTS AND DISCUSSION}

Fig. 15 shows short circuit voltage waveforms for the piezoelectrically actuated contact system and the constant velocity $\left(1 \mathrm{~ms}^{-1}\right)$ system.

In Figs. 15-17, the data are overlaid on idealised contact trajectories. In the case of the piezoelectrically operated contact system the trajectory was calculated using (3) and (6) as described above assuming an effective mass of $2 \mathrm{~g}$ to simulate the mass of the moving contact. For the "driven" contact system a constant contact velocity of $1 \mathrm{~ms}^{-1}$ is shown.

The contact opening time was obtained from the initial rise in the arc voltage and the contact trajectory calculation started at this point. The results show that the arc successfully transferred from the contact system into the arc stack and effective current limitation was achieved with both contact systems.

There is a limited amount of information that can be obtained from examination of the voltage results alone. The use of the arc imaging system makes possible the independent measurement of the anode and cathode root movements. In particular we are interested in the first few milliseconds of arc movement.

In the following discussion, approximate values are user-derived from the data in Figs. 16 and 17. In the case of the anode (Fig. 16) on the $1 \mathrm{~m} / \mathrm{s}$ moving contact, the anode moves rapidly $2.5 \mathrm{~mm}$ after $1 \mathrm{~ms}$ at a contact gap of $0.6 \mathrm{~mm}$, after this movement the anode root remains static for $2 \mathrm{~ms}$ until the arc transfers rapidly away from the contact region, at a contact gap of $2.5 \mathrm{~mm}$.

On the significantly slower piezoelectrically operated contact the anode remains static for $3.8 \mathrm{~ms}$ until the contact gap reaches approximately the same value as for the initial movement in the constant velocity opening system $(0.6 \mathrm{~mm})$. The anode root is then able to transfer rapidly away from the contact system and into the arc stack.

The observation that the arc movement occurs at the same contact gap for both contact systems is in accord with previous studies [10], [11] where it was shown that a minimum contact gap is requirement for arc motion. However, in this study the most significant delay in moving away from the contact region 


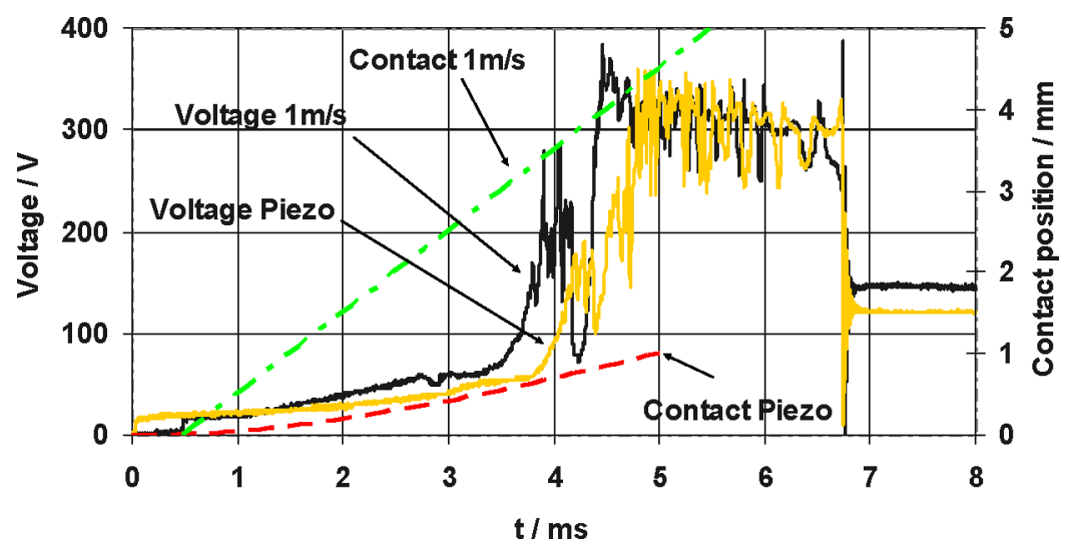

Fig. 15. Arc voltages for piezoelectric and constant velocity $1 \mathrm{~ms}^{-1}$ contact systems. Contact trajectories for the two systems are shown (dashed lines). (Color version available online at http://ieeexplore.ieee.org.)

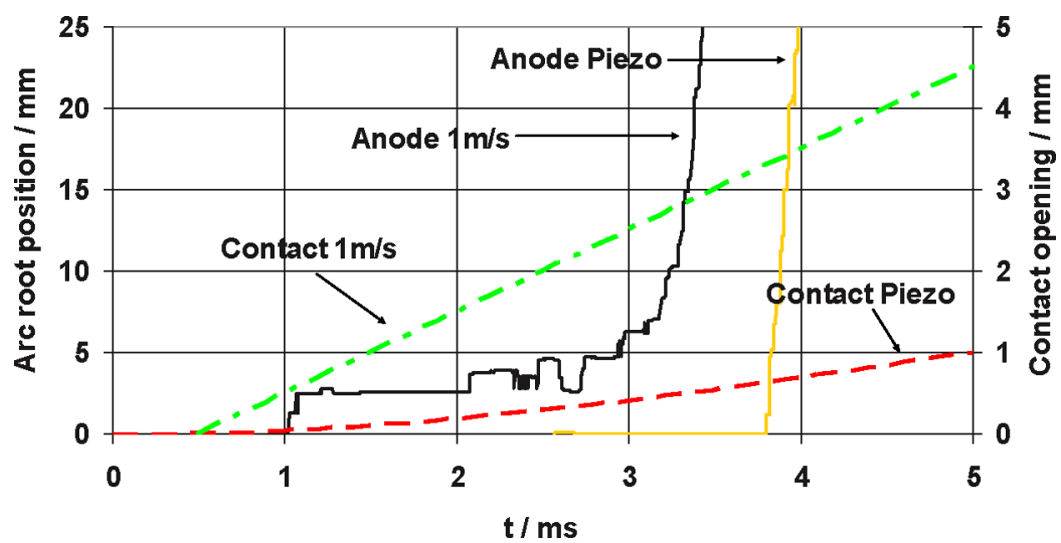

Fig. 16. Anode root displacement compared between piezoelectric and constant velocity $\left(1 \mathrm{~ms}^{-1}\right)$ contact systems. Contact trajectories for the two systems are shown (dashed lines). (Color version available online at http://ieeexplore.ieee.org.)

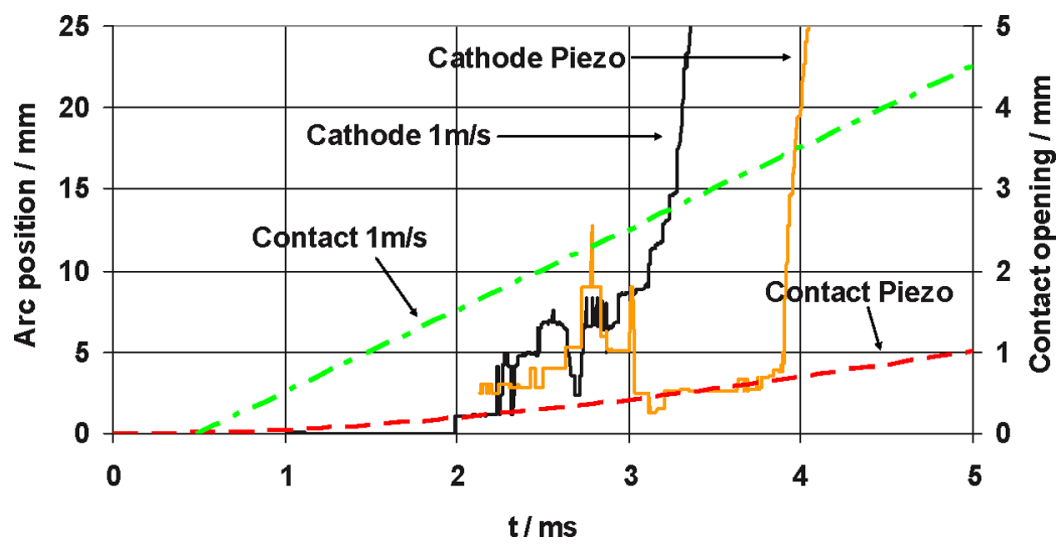

Fig. 17. Cathode root displacement compared between piezoelectric and constant velocity $1 \mathrm{~ms}^{-1}$ contact systems. Contact trajectories for the two systems are shown (dashed lines). (Color version available online at http://ieeexplore.ieee.org.)

occurs after this initial arc motion, and in these tests the onset of rapid arc motion bore no relationship to the contact separation. As seen in Fig. 16 there is not a very large difference in the time of rapid arc motion despite significantly different contact velocities. In this case it is possible that the delay is caused by the transfer of the arc from the moving contact to the arc runner, where factors such as gas flow have a strong influence [3].

The cathode root on the fixed contact shows a more gradual movement for both the piezoelectrically operated and constant velocity contact systems. The constant velocity system shows an initial slow arc root movement of approximately $5 \mathrm{~ms}^{-1}$ followed by rapid arc motion at the same time as the anode. The piezoelectric system shows some erratic movement between 2-3 ms. The onset of rapid arc motion occurs at the same contact gap as the start of the cathode movement in the constant velocity system.

The effect of the contact opening velocity on arc erosion has not been investigated in this study, but the longer dwell time in the region of arc formation is likely to increase contact erosion. However, the direct electromechanical coupling of a piezoelectric actuator means that it would be possible to tailor the contact 
opening trajectory simply by controlling the charge on the actuator. It is known that the opening velocity profile can have a significant effect on the contact erosion [12], and it may therefore be possible to optimize the contact opening trajectory for minimum contact erosion. This is an important area for further study.

These initial results show that despite a low contact opening velocity on the piezoelectrically operated contacts (due to the large mass of the moving contact) the transition to rapid arc motion away from the contact region occurs only slightly later than the constant velocity system. Clearly the contact mass is a significant factor in the speed of operation of the contact system. However, the overall effect on the arc control is not as significant as might be expected on the basis of a minimum contact gap requirement. Other factors such as optimization of the gas flow to permit rapid transfer off the moving contact are significant. Successful current limitation was therefore possible using a piezoelectric actuator. Even so there is considerable scope for improving the effectiveness of the piezoelectrically operated system not only by increasing the contact velocity but also by further development of the arc chamber to provide enhanced performance at low contact opening velocity.

\section{CONCLUSION}

This paper demonstrates how a piezoelectric actuator can be used as part of the actuation system in a circuit breaker mechanism. A methodology is presented for the analysis and design optimization of piezoelectric actuator based contact system. A piezoelectrically operated system was implemented in a test chamber and used to demonstrate successful current limiting performance.

- The performance of a commercially available piezoelectric ceramic actuator is assessed for suitability for use in a circuit breaker mechanism.

- The piezoelectric actuator is able to achieve contact velocities in the range required for current limitation for an arc chamber optimized for low contact opening velocity.

- The moving contact mass can significantly reduce the contact opening velocity and is therefore a significant design parameter.

- Short circuit tests show effective current limiting performance comparable to a constant velocity $\left(1 \mathrm{~ms}^{-1}\right)$ contact system.

\section{REFERENCES}

[1] J. W. McBride and P. M. Weaver, "Review of arcing phenomena in low voltage current limiting circuit breakers," Proc. Inst. Elect. Eng., vol. 148, no. 1, pp. 1-7, Jan. 2001.

[2] J. W. McBride, K. Pechrach, and P. M. Weaver, "Arc root commutation from moving contacts in low voltage devices," IEEE Trans. Comp. Packag. Technol., vol. 24, no. 3, pp. 331-336, Sep. 2001.

[3] P. M. Weaver, K. Pechrach, and J. W. McBride, "The energetics of gas flow and contact erosion during short circuit arcing," IEEE Trans. Comp. Packag. Technol., vol. 27, no. 1, pp. 51-56, Mar. 2004.

[4] J. W. McBride, K. Pechrach, and P. M. Weaver, "Arc motion and gas flow in current limiting circuit breakers operating with a low contacts switching velocity," IEEE Trans. Comp. Packag. Technol., vol. 25, no. 3, pp. 427-433, Sep. 2002.

[5] S. C. Powell, "The development of a low cost, high performance piezo actuator for high volume manufacture," in Proc. 7th Int. Conf. New Actuators (Actuator'00), Bremen, Germany, Jun. 2000, pp. 45-48.

[6] A. J. Moulson and J. M. Herbert, Electroceramics. London, U.K.: Chapman and Hall, 1990.
[7] P. M. Weaver, A. Ashwell, Y. Zheng, and S. C. Powell, "Extended temperature range piezo actuator system with very large movement," in Proc. SPIE 10th Annu. Int. Symp. Smart Structure Materials-Active Materials: Behavior and Mechanics, San Diego, CA, Mar. 2-6, 2003, pp. 484-492.

[8] Servocell. (2005) Servocell Handbook. [Online] Available: http://www. servocell.com

[9] B. Jaffe, W. R. Cook, and H. Jaffe, Piezoelectric Ceramics. New York: Academic, 1971.

[10] W. Rieder, "Interaction between magnet-blast arcs and contacts," in Proc. 28th Holm Conf. Electrical Contacts, 1982, pp. 3-10.

[11] E. M. Belbel and M. Lauraire, "Behavior of switching arc in low-voltage limiter circuit breaker," IEEE Trans. Comp., Hybrids, Manufact. Technol., vol. 8, no. 1, pp. 3-12, Mar. 1985.

[12] J. W. McBride and M. A. Sharkh, "The effect of contact opening velocity and the moment of contact opening on the $\mathrm{AC}$ erosion of $\mathrm{Ag} / \mathrm{CdO}$ contacts," IEEE Trans. Comp., Packag., Manufact. Technol. A, vol. 17, no. 1, pp. 2-7, Mar. 1994.

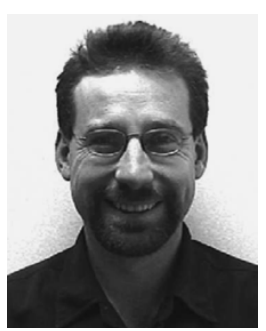

Paul M. Weaver received the B.A. degree (with honors) in natural science from the University of Cambridge, Cambridge, U.K. and the Ph.D. degree in aeronautical engineering from the University of Southampton, Southampton, U.K.

$\mathrm{He}$ is a Research Manager at Servocell, Ltd., Harlow, U.K. (a manufacturer and developer of piezoelectric actuators and circuit protection devices). He has been working in industry since 1993 in the research and development of circuit breakers and related switching systems and has published widely in this field. Prior to this he was a Research Fellow at Southampton University researching short circuit arc phenomena. Research interests include switching arc phenomena, smart materials actuation, and sensor technologies.

Dr. Weaver is a member of the Institute of Electrical Engineers (IEE).

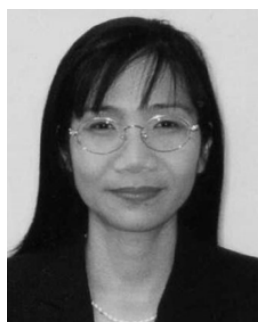

Kesorn Pechrach received the B.Eng. degree in electrical engineering from Khon Kaen University, Khon Kaen, Thailand, in 1992, the M. Eng. degree in energy technology from the King Mongkut's University of Technology, Thonburi, Thailand, in 1997, and the $\mathrm{PhD}$. degree in electro-mechanical engineering from the University of Southampton, Southampton, U.K., in 2003.

She is Managing Director of the technology company Ronsek, Ltd., Hertfordshire, U.K. She has worked for consulting engineer companies as a lead electrical engineer since 1992. Her responsibilities included the design and engineer supervision of electrical facilities for industrial plants, commercial building, roadways, refineries and HV substations. She was was a Post-Doctoral Research Fellow at the University of Southampton.

Dr. Pechrach is a member of the Institute of Electrical Engineers (IEE) and a Chartered Electrical Engineer of the Engineering Institute of Thailand.

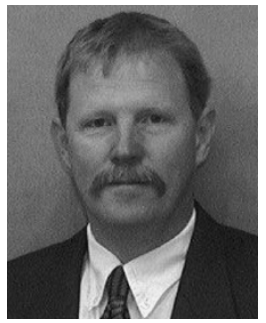

John W. McBride received the M.S. degree in aeronautical engineering from the University of Southampton, Southampton, U.K., in 1978 and the $\mathrm{Ph} . \mathrm{D}$. degree in electrical contact phenomena from Plymouth University, Plymouth, U.K., in 1986.

Since 1987, he has been Lecturer, Senior Lecturer, and now Professor of Electromechanical Engineering in the School of Engineering Science, University of Southampton. He is Chair of the Electromechanical Research Group. His research interests include instrumentation; surface metrology, applied to optics, MEMS, wear analysis, early sound recordings, and electrical contact phenomena.

Dr. McBride is an Associate Editor of the IEEE TRANSACTIONS ON COMPONENTS AND PACKAGING TECHNOLOGIES and a member of the Organizing Committee, IEEE Holm Conference on Electrical Contacts. 